\title{
Review
}

\section{The Role of Liquid-Based Preparation in the Evaluation of Endometrial Cytology}

\author{
Yoshiaki Norimatsu $^{\mathrm{a}}$ Kenji Yanoh $^{\mathrm{b}}$ Tadao K. Kobayashic \\ ${ }^{a}$ Department of Medical Technology, Ehime Prefectural University of Health Sciences, Tobe, ${ }^{b}$ Department of \\ Gynecology, Suzuka General Hospital, Suzuka, and ${ }^{\mathrm{C} C a n c e r}$ Education and Research Center, Osaka University \\ Graduate School of Medicine and Health Science, Osaka, Japan
}

\section{Key Words}

Endometrial cytology · Endometrial carcinoma .

Liquid-based preparation

\begin{abstract}
Objective: Liquid-based preparation (LBP) of the endometrial lesions is an important diagnostic tool for a variety of endometrial abnormalities because of its simplicity and high quali-quantitative diagnostic yield. We aimed to investigate the LBP method for endometrial cytology to evaluate both benign and abnormal endometrial lesions. Study Design: LBP is a semiautomated methodology that has recently become widely available and has gained popularity as a method of collecting and processing both gynecologic and nongynecologic cellular specimens. Results: Some peculiar endometrial cytoarchitectural features were described using LBPs. These were advantageous to screen as compared to conventional slides due to a smaller screening area and an excellent quality of cell preparations. Conclusions: LBP is a useful tool in the cellular diagnosis and follow-up of endometrial abnormalities, which remains complementary to the emerging molecular diagnostic cytopathology. The study of LBPs from endometrial cytology could be challenging since it is affected by numerous look-alikes and diagnostic pitfalls. This review discusses these various entities and takes into consideration the ancillary techniques that may be useful in the diagnostic procedure.

(c) 2013 S. Karger AG, Basel
\end{abstract}

\section{Introduction}

Population-based cancer data in Western countries, particularly in the USA, shows a significant increase in the incidence of endometrial cancer starting in the early 1970s [1]. It is also known that the incidence of endometrial cancer has risen each year in Japan over a period of 30 years [2]. Therefore, the early detection of endometrial cancer is important for the improvement of the longterm survival rate of patients, and endometrial cytology has been widely used in Japan as the main screening procedure [3]. Direct cellular sampling of the endometrial vault increases the sensitivity of adenocarcinoma detection. Although a number of sampling methods have been introduced over the years, the sensitivity for the detection of endometrial adenocarcinoma using direct endometrial sampling depends in part on whether tissue fragments are obtained [4]. Endometrial cytology is a great challenge to both cytopathologists and cytotechnologists. The possibility of obtaining high-quality endometrial samples could be of great help in unifying the diagnostic terminology and in permitting a better dialogue among cytotechnologists, cytopathologists and clinicians; these features constitute the premises for the routine introduction of the test in the gynecologic practice [5-7]. In the past the adoption of endometrial cytology as a diagnostic procedure has been hampered by the difficulties that arose in interpreting the cellular findings due to several factors

\section{KARGER}

E-Mail karger@karger.com

www.karger.com/acy
(C) 2013 S. Karger AG, Base

0001-5547/13/0575-0423\$38.00/0
Correspondence to: Dr. Tadao K. Kobayashi

Cancer Education and Research Center

Osaka University Graduate School of Medicine and Health Science

Osaka 520-0865 (Japan)

E-Mail tkkobaya@ hotmail.co.jp 
intrinsic to conventional slides, such as the presence of excess blood and of dense, overlapping cell groups in many samples, disturbing the interpretation and the cytologic diagnosis. Another important challenge in the interpretation of endometrial cell samples was also represented by the complex physiology of the endometrium. Recently, the use of liquid-based preparation (LBP), characterized by a reduced blood and mucus contamination and by a uniform distribution of cells in a thin layer on the slide, has provided an opportunity to reevaluate the role of cellular diagnosis in endometrial cytology. Thinlayer or LBP technique, originally developed for gynecologic cervical smears, has progressively gained consensus after being applied in both nongynecologic and fine-needle aspiration cytology. The material remaining in the vial after cellular diagnosis can be used for ancillary techniques such as immunocytochemistry, flow cytometry and molecular biology. In fact, the LBP method enables storage of a variable amount of cells. Recently, several studies have described the cellular assessment of endometrial lesions by using cytoarchitectural criteria on LBPs [8-15]. The above described advantages of LBPs versus conventional slides suggest the replacement of conventional slides with LBPs in the routine cytologic evaluation of endometrial cell samples.

Several investigations have suggested that LBP may achieve a diagnostic sensitivity as high as that found in conventional preparations [16-19]. Therefore, LBP has become the main technique for cervical cytology in the USA, with about $90 \%$ of the tests being liquid-based cytology. In this review, we will discuss the cellular evaluation of LBPs in endometrial samples (including normal endometrium, endometrial hyperplasia $(\mathrm{EH})$, well-differentiated adenocarcinoma and disordered endometrium associated with anovulation - the so-called endometrial glandular and stromal breakdown, EGBD) by using cytoarchitectural criteria.

\section{Processing of Endometrial LBP Method}

The improvement of the diagnostic capacity of endometrial cytology leading to the introduction of LBP method suggests that this procedure should be routinely used in endometrial diagnosis. The main advantages of this procedure are the reduction in confounding factors, the distribution of cells on a thin layer and the possibility to obtain more slides from the same sample. The two LBP technologies currently in use include ThinPrep (Hologic Inc., Bedford, Mass., USA) and SurePath (BD Diagnos- tics, Burlington, N.C., USA) and several groups have reported their experience either by using ThinPrep [10, 11, $14,15]$ or SurePath $[8,9,12,13]$ methods. There are subtle differences between ThinPrep and SurePath preparations which reflect different sampling devices, collection media and processing techniques [20-23].

\section{Cellular Findings in LBP Method Using Cytoarchitectural Features}

The adequacy of LBP for endometrial sample has already been described in the literature. Garcia et al. [23] noted that LBP endometrial cytology has good specificity and positive predictive value for the detection of endometrial abnormalities and has a lower rate of unsatisfactory diagnoses compared to biopsy. It has been reported [10, 11] that examination of just one slide provides sufficient material for cytological evaluation of an endometrial sample. Therefore, although the preparation area of LBP is smaller than conventional methods, LBP contains cells of adequate quantity and quality for a possible diagnosis $[8,9]$.

\section{Normal Endometrial Cells}

\section{Proliferative Endometrium}

Proliferative endometrium (PE) shows uniform straight to curvilinear tubular or flat epithelial sheets with cohesion of the endometrial stromal cells (tubular or sheet-like pattern; fig. 1a). The nuclei of epithelial cells are closely packed, oval to cigar shaped with smooth contours, evenly dispersed chromatin and small-sized nucleoli. Mitoses of normal configuration may be seen.

\section{Secretory Endometrium}

Early secretory endometrium (SE) is similar to PE but with a lower nuclear/cytoplasmic ratio, smaller inconspicuous nucleoli, absent mitoses and greater spacing of nuclei. Mid-SE shows a honeycomb pattern (fig. 1b) with increased cytoplasm over that of early SE, and accordionpleated glands which are the three-dimensional equivalent of 'saw-toothed' glands (fig. 1c). Nuclei are larger than those of PE, rounded and vesicular, and display a fine chromatin pattern.

\section{Atrophic Endometrium}

Atrophic endometrium (AE) is similar to PE but nuclear crowding and overlapping is not as striking as in PE. 
Fig. 1. Normal endometrial cells. a PE; showing a uniform, straight tubular gland with cohesion of the endometrial stromal cells to the margins of the gland. b SE; showing a honeycomb pattern, which increased cytoplasm over that of PE. c MidSE; showing the three-dimensional equivalent of saw-toothed glands. d Blood vessel; because of a clean background in LBCP, vascular identification was easy. A vascular cluster appears as a bundle of spindleshaped cells including endothelial cells and/or perivascular smooth muscle cells. SurePath LBP, Papanicolaou stain. Original magnifications: $\times 20(\mathbf{a}, \mathbf{b}) ; \times 40(\mathbf{c}) ; \times 10$ (d).

Fig. 2. a, b EH without atypia. Irregular dilation or branched pattern is noted in tubular glands. The maximum width of a gland is more than twice that of its minimum width and shows cohesion of the endometrial stromal cells to the margins of the gland. SurePath LBP, Papanicolaou stain. Original magnifications: $\times 20(\mathbf{a}, \mathbf{b})$.
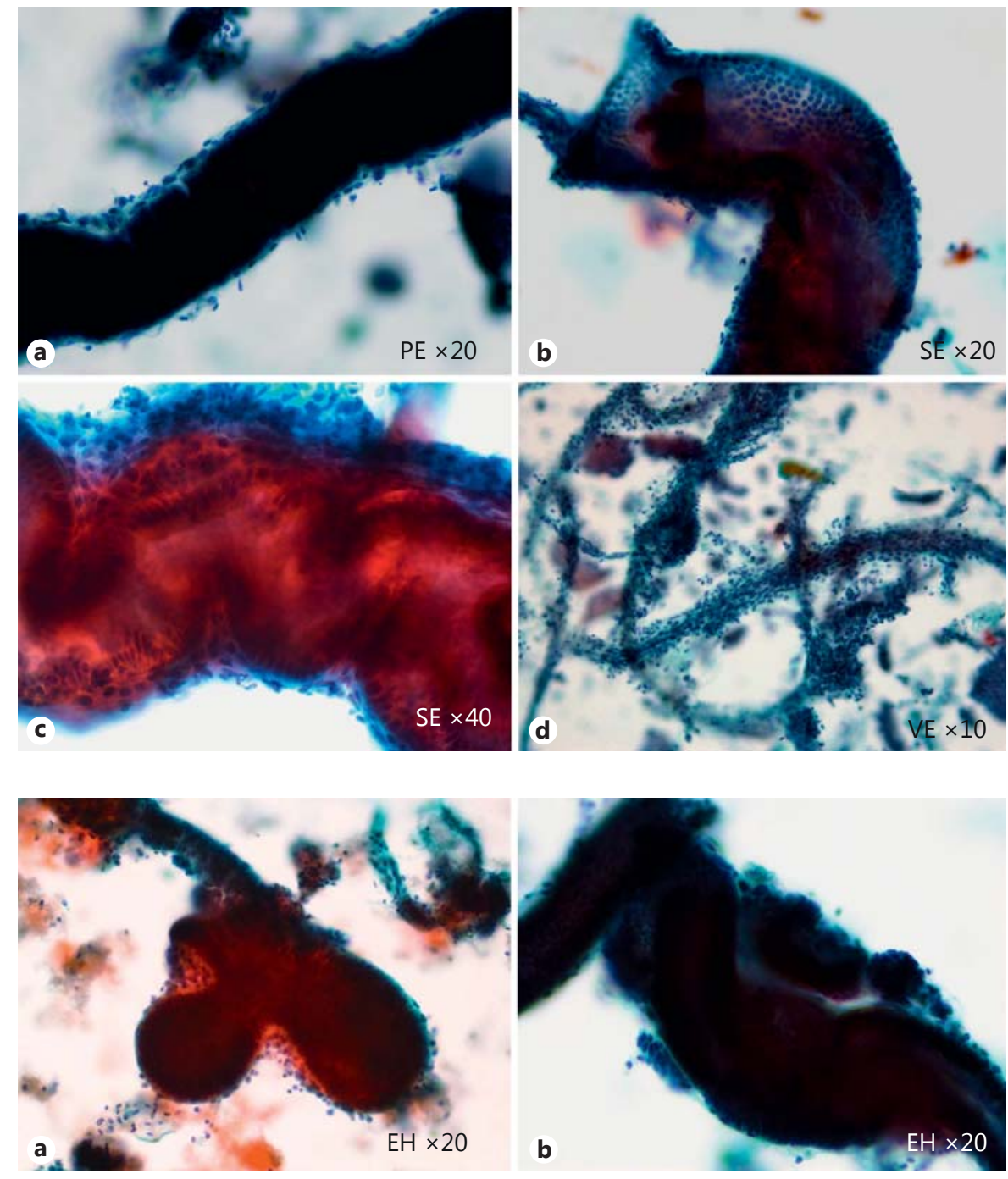

The cells display uniform round nuclei and are generally arranged in small monolayer sheets with distinct cytoplasmic boundaries; mitoses are scarce or absent.

\section{Blood Vessels in LBP}

These are identified by an elongated bundle of spindleshaped cells including endothelial cells and/or perivascular smooth cells (fig. 1d). Vascular identification is easy, because the background in LBP is clean.

\section{Cellular Findings in EH}

\section{EH without Atypia}

Simple EH is characterized by a large variability in glandular size. Some glands are large and cystically di- lated, whereas others are of normal or even unusually small size. Complex EH is composed of crowded glands with a reduction in the amount of intervening stroma [24]. Furthermore, with increasing degrees of architectural abnormality, glands become complex and branched, with irregular glandular outlines, and produce a fingerin-glove pattern. Therefore, this cytoarchitecture is well reflected in LBPs, and glands with irregular dilation and branching appear to be characteristic of $\mathrm{EH}$ in the cellular sample (fig. 2a, b). In patients with $\mathrm{EH}$, the cell clumps could represent either cells from normal mucosa or abnormal groups shedding from hyperplastic mucosa. Meisels and Jolicoeur [25] suggested that the considerable widening of slender tubes should be regarded with interest for the diagnosis of hyperplasia and, according to Skaarland [26], tissue fragments dominated by branching 
Fig. 3. G1. a, b Irregular protrusion patterns recognize some irregular small projections at the edges of cell clumps. The margin of the cytoplasm of those small projections is clearly observed. c As for the papillotubular patterns, endometrial gland shows a papillary growth pattern with irregular branching and projections. Cohesion of the endometrial stromal cells is not noted at the margins of the gland. $\mathbf{d}$ When the papillary structure is complex and confluent, much glandular space is formed and back-to-back structures with a cribriform pattern are also recognized. SurePath LBP, Papanicolaou stain. Original magnifications: $\times 20(\mathbf{a}, \mathbf{c}, \mathbf{d}) ; \times 40(\mathbf{b})$.
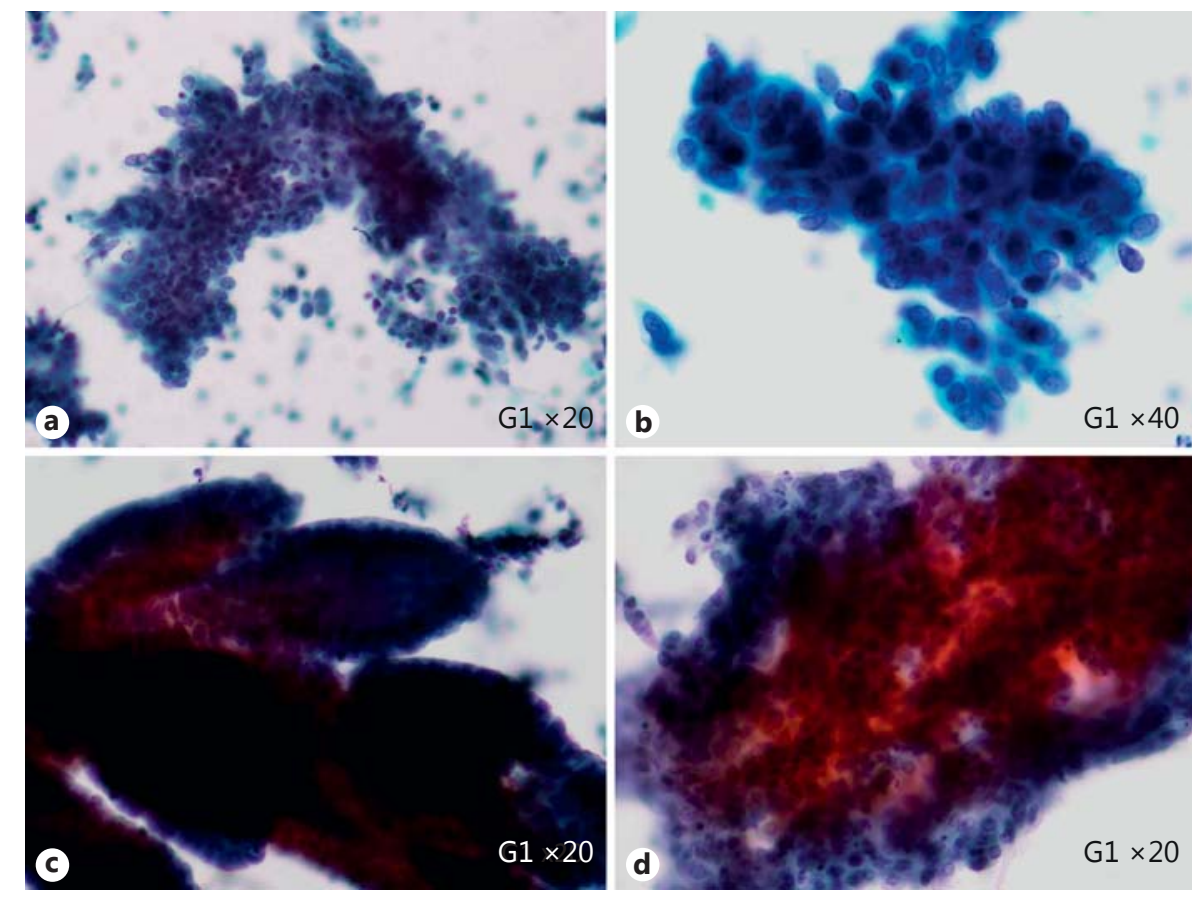

small and larger glands were described in adenomatous hyperplasia. In a paper by Coscia-Porrazzi [27], benign complex hyperplasia was characterized by branching glandular structures comparable to those we have observed in the current study. From the cytologic point of view, we believe that the recognition of glands with a dilated or branched pattern is a useful feature in $\mathrm{EH}[6,7]$. The basic cellular features of glandular epithelium (apart from the overall architecture) resemble those of PE glands in normal endometrium; the cytoplasm is commonly scant and the nuclei are isomorphic with finely granular chromatin and small or absent nucleoli.

\section{EH with Atypia}

In our current study, we found that $\mathrm{EH}$ with atypia (AEH) consists essentially of two cellular patterns: glands with a dilated or branched pattern and glands with an irregular protrusion $[6,9]$. However, no correlation between these cytologic and histologic categories appeared to exist, although we described a continuum of changes from atypical to carcinoma. The lack of correlation is most evident when the histologic category of grade 1 adenocarcinoma is compared with the cytologic category of $\mathrm{AEH}[24,28-32]$. In fact, the majority of women who have cytologic AEH do not have an atypical EH on histology. In AEH, the cytoplasm becomes evident and the nuclei may show a moderate pleomorphism.

\section{Grade 1 Endometrial Adenocarcinoma}

The following histopathologic features are evident with grade 1 endometrial adenocarcinoma (G1) [28, 29, 31, 33]: (1) a complex papillary growth pattern with thin fibrous processes lined by epithelium; (2) papillary epithelium lacking a fibrovascular core, and (3) a confluent glandular pattern creating a cribriform structure. This cytoarchitecture could represent either an irregular protrusion pattern (fig. 3a, b) or a papillotubular pattern (fig. 3c, d) characteristic of the G1 in the cellular sample. In these samples no adhesion of the endometrial stromal cells to the margins of the glands was found. The predominant frequency of the abnormal cell clumps in G1 is fairly characteristic. Byren [34] found that papillary, pseudopapillary and fimbriated structures were present within the tissue fragments of malignant smears. According to Skaarland [26], tissue fragments demonstrating papillary formations were occasionally noted in malignant conditions. They are believed represent to the three-dimensional analogues of 'glands with irregular protrusion pattern' or of a 'papillotubular pattern' $[6,9]$ in LBP.

Meisels and Jolicoeur [25] and Morse [35] reported that overlapping nuclei are 'useful' diagnostic criteria for endometrial lesions in conventional cellular preparation (CCP). Similarly, with LBP, Papaefthimiou et al. [11] reported that overlapping of two nuclei was observed in en- 
dometrial adenocarcinoma. However, the degree of overlapping between the nuclei in hyperplasia with or without atypia was slight. To evaluate the diagnostic value of endometrial cytology, Norimatsu et al. [9] tried to compare the degree of overlapping of nuclei in endometrial carcinoma (EC) and normal endometrium. The study showed that the degree of overlapping decreased significantly from $\mathrm{EC}$ to proliferative, secretory and $\mathrm{AE}$ in both $\mathrm{CCP}$ and LBP, so that the quantitation of the degree of overlapping is necessary to distinguish $\mathrm{EC}$ from normal endometrium. However, while there is no significant difference in the extent of overlapping nuclei between CCP and LBP with regard to normal endometrial types, LBPs show a higher degree of overlapping in EC $(p<0.0001)$ than CCPs. This new finding indicates that the degree of overlapping nuclei in EC is enhanced by LBP compared with $\mathrm{CCP}$, which is also very useful in the diagnosis of EC. It is assumed that the finding reflects a characteristic of the SurePath LBP method, whereby when the endometrial cells in clumps are collected into the vial the cellular architecture is preserved by the fixative. When making the smear, these clumps are disrupted onto the glass slide surface, either because of their specific gravity, or by the cellular electric charge (glass slide surface is ' + ', cell is '-'). Thus, in SurePath LBP, it seems that the original architecture is retained in the preserved cell clumps.

\section{Endometrial Glandular and Stromal Breakdown}

Anovulatory cycles may lead to dysfunctional uterine bleeding (DUB) with changes in the endometrium that are similar to $\mathrm{EH}$ in cellular preparations. This type of bleeding occurs frequently and many patients are referred to the gynecology out-patient clinics for evaluation. Therefore, it is necessary that $\mathrm{EH}$ is correctly identified by cytology, with appropriate careful follow-up [24]. Recognition of the cellular findings in anovulatory cycle endometrium is also essential if $\mathrm{EH}$ is to be ruled out. The appearance of atypical glandular cells in cervicovaginal smears was reported in 1975 by Ehrmann [36] in two cases with false positive cytology, which were retrospectively thought to be associated with endometrial stromal breakdown. Since then, there has been no description of atypical cells in anovulatory cycle endometrium. Uterine bleeding that occurs at irregular intervals (which can be prolonged and excessive, or scanty and prolonged), is considered as DUB if there is no easily assignable cause. Anovulatory cycles are the most common cause of DUB in women in their reproductive age [37]. There are vari- ous references to the histological features of DUB $[38,39]$. Sherman et al. [37] described the clinical and pathological changes in hormonally misresponsive endometrium associated with anovulatory cycles. These changes are characterized by extensive fragmentation of PE with anovulatory bleeding which is referred to as EGBD [40].

The EGBD cases in which histopathological diagnoses were obtained by endometrial curettage have been studied in order to improve the accuracy of cellular diagnosis. At the time of the menopause anovulatory cycles frequently cause changes in simple AE, leading to abnormal bleeding in many cases. The endometrial changes may simulate $\mathrm{EH}$, leading to difficulty in cellular interpretation. Anovulatory DUB due to raised estrogen levels is more often associated histologically with persistent proliferative phase endometrium and hyperplasia. It is caused by prolonged endogenous hyperestrogenism, unopposed by progesterone. Hence, the origin of breakthrough bleeding in persistent PE and hyperplasia can be traced to stromal breakdown, which is associated with pools of extravasated erythrocytes, platelet/fibrin thrombi in capillaries and repair-related changes [41]. Therefore, a diagnosis of EGBD should be considered when the cytomorphological changes reveal fragmented clusters of endometrial glands, and condensed clusters of stromal cells (fig. 4a). These cellular findings are significant, are commonly found and are the characteristic cellular changes of EGBD.

\section{Papillary Metaplastic Change}

The problems of interpretation of endometrial cytology in anovulatory bleeding described above are compounded by various types of hormonally induced metaplastic changes in the endometrium as the histological changes progress from benign to malignancy [42-46]. Frequently, in the process of endometrial glandular and stromal breakdown, metaplastic changes occur in the endometrial surface epithelium $[37,46,47]$. The studies by Ehrmann [36] and Gribaudi and Alasio [48] showed that the cellular pattern of these metaplastic changes is similar to that of endometrial hyperplastic cells and, in many respects also to that of endometrial adenocarcinoma cells, creating diagnostic pitfalls in the cytomorphology. Despite its frequent occurrence and potential for confusion with other types of endometrial pathology, very little has been written about the cellular manifestations of such lesions in endometrial samples. Recently, we have found that the presence of metaplastic cells in cytological samples showing EGBD cases was significantly higher than in other endometrial lesions. Both eosinophilic and ciliated 
Fig. 4. EGBD. a CCSC is condensed and forms compact nests with hyperchromatic nuclei and little or no cytoplasm. b MCIP is composed of metaplastic cells showing thick eosinophilic cytoplasm and the rounded nucleus with slight swelling. Some irregular small projection figures are seen from the margins of cell clumps. c MCIPcontaining condensed stromal clusters are accompanied by condensed stromal clusters into cell clumps (indicated by white arrows). d LGB; this is a light green-stained extracellular substance observed in CCSC and in the background: a nonuniform granular pattern or fiber pattern form was respectively recognized in samples containing LGBs. SurePath LBP, Papanicolaou stain. Original magnification: $\times 40(\mathbf{a}-\mathbf{d})$.
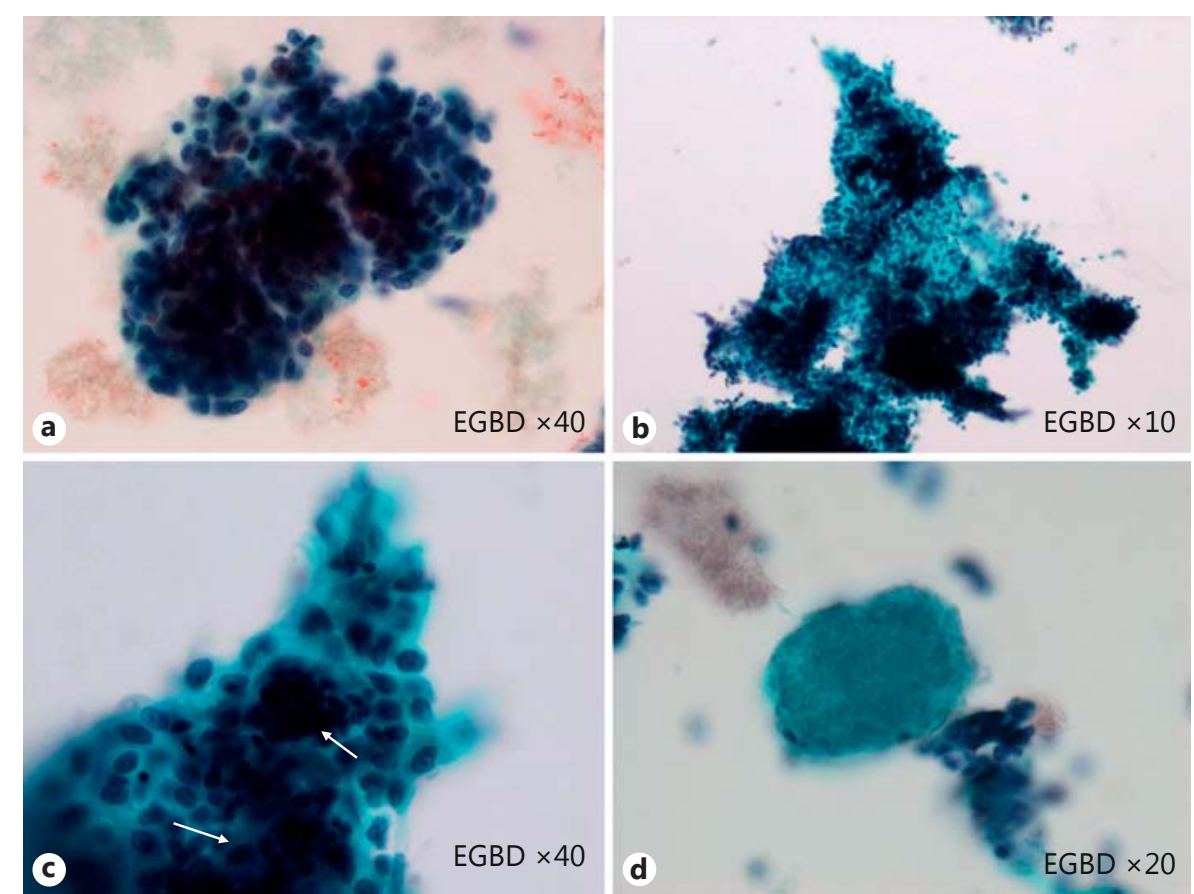

metaplasia were recognized [49]. Because metaplasias originate in the presence of high estrogen levels, the finding is of relevance to $\mathrm{EH}[37,41,44,46]$. Papillary metaplasia involves the endometrial surface epithelium [37, 42-44], occurring as a structural atypia in cellular material. Distinction from EH can be particularly difficult as the metaplastic cells may be present in abnormal cell clumps in samples from women showing EGBD. The metaplastic cells show thick eosinophilic cytoplasm and rounded, slightly swollen nuclei; some irregular small projections can be seen from the edges of the cell clumps. We have defined these as metaplastic clumps with irregular protrusion (MCIP; fig. 4b, c). In EGBD cases, MCIP appears to be common, occurring in $90.6 \%$ of our cases, and they were rather characteristic in comparison with other lesions [49]. Papillary metaplasia, also known as eosinophilic syncytial change, papillary syncytial change and surface syncytial change, is seen with EGBD on the endometrial surface epithelium.

Sherman et al. [37] noted that papillary syncytial metaplasia is an epithelial alteration that is associated with stromal breakdown and that these lesions typically involve the surface epithelium. Histopathological findings of acute endometrial breakdown, as previously shown by Zaman and Mazur [50] who reported such changes, were intimately admixed with foci of papillary syncytial change along the surface epithelium. The papillary metaplasia in their cases was characterized by stratified eosinophilic cells often forming small papillary tufts that lacked connective tissue support; the degree of nuclear enlargement, pleomorphism and irregularity is comparatively moderate $[38,42,47]$. The MCIP which we have observed are considered to correspond to this type of papillary metaplasia. Sherman et al. [37] stated that the condensed stromal cell changes observed in the endometrium are associated with anovulatory cycles. There still remains the problem of understanding the pathogenesis of these changes. Therefore, we classified three morphological variants of MCIP and suggested their tissue of origin. MCIP was present with condensed stromal clusters in 93.1\% of EGBD cases, which was highly significant, compared to other lesions [49]. In histopathological samples of EGBD, papillary metaplasia was seen within endometrial surface epithelium, and was both included in and attached to the condensed stromal clusters [37, 42, 47, 50]. Papillary metaplastic tissue forms microscopic mounds on the endometrial surface overlying condensed stromal cells, as it has been described by Sherman et al. [37]. Zaman and Mazur [50] have shown that the dense clusters of endometrial stroma, often with a cap of epithelium, are the defining features of the process of acute endometrial breakdown. Lehman and Hart [47] noted that the presence of rounded clumps of endometrial stromal cells associated with nuclear debris and neutrophils are a char- 
acteristic appearance. However, these lesions are neither pathological or metaplastic, but, rather, they are a seemingly reparative tissue response following endometrial breakdown bleeding. Therefore, the appearance of MCIP with condensed stromal clusters is thought to originate from papillary metaplasia (fig. $4 \mathrm{~b}, \mathrm{c}$ ). They occur on the endometrial surface epithelium and the appearance of MCIP can be of great help in confirming the suggestion of EGBD endometrium [49].

\section{Light Green Body}

In our recent study [51], we investigated the condensed cluster of stromal cells (CCSC) in EGBD cases in detail. The substance which stained in light green stain (light green body; LGB) was recognized within the cluster and in the background (fig. 4d). LGBs showed either a nonuniform granular pattern or fiber pattern form. The occurrence of CCSC including an LGB was $44.8 \%$ and an average of 2 LGBs was found per case. In addition, the occurrence of LGBs in the background was $91.4 \%$ and an average of 4 LGBs was found per case. As a result, it seemed that LGBs may become a useful index for a correct cellular diagnosis of EGBD. Hence, we tried to speculate on the nature of LGBs. Immunohistochemistry on paraffin-embedded tissue sections gave positive results for CD31, factor VIII and CD42b, but fibrinogen staining gave a negative or weakly positive reaction. The results of immunocytochemistry on LBP were comparable: LGB stained positively for CD31, factor VIII and CD42b. However, due to intense and diffuse background staining, the reaction for fibrinogen could not be evaluated. As for the histological features of EGBD, it was reported that the endometrium often displays thin-walled ectatic venules that may contain prominent fibrin thrombi, a feature seldom encountered in normal menstrual mucosa. Moreover, it was suggested that the bleeding is caused by disruption of the capillaries that contain platelet/fibrin thrombi [37, 39, 41]. Likewise, Maksem et al. [52] showed that fibrin thrombi are often intimately associated to discrete areas surrounding stromal breakdown in tissue preparations (HE stain), and platelet/fibrin thrombi decorated by adherent stromal cells were identified in cellular preparations (Pap stain).

The CD31 molecule is expressed on the surface of platelets, monocytes, granulocytes and $\mathrm{B}$ cells, and the properties of CD31 antigen suggest that it is involved in interactive events during angiogenesis, thrombosis and wound healing [53]. The factor VIII-related antigen (human von Willebrand factor) has functional binding domains to platelet glycoprotein, collagen and heparin, and it plays an important role in platelet adhesion and aggregation [53, 54]. Furthermore, CD42b acts as an adhesion receptor for the von Willebrand factor and thrombin [55]. From the above-mentioned results, it was proved that LGBs in an EGBD case were thrombi mainly formed by blood platelets. The nonuniform granular pattern or mesh-like fiber pattern in LGBs could be explained with a mesh-like fibrin net entrapping platelets. Since LGBs were exclusively identified in the context of EGBD, their identification seems to be another useful diagnostic cytological criterion of EGBD [51].

\section{Nuclear Findings in LBP: Comparison of EGBD and G1}

With regard to the histological changes in EGBD, as the ground substance undergoes dissolution, the normal architecture collapses, and isolated, fragmented glands come to lie in haphazard disarray without surrounding stroma. The stromal cells condense and form compact nests of cells with hyperchromatic nuclei and little or no cytoplasm. The contemporary presence of papillary tufts shedding from syncytial metaplasia admixed to the degenerated stromal cells may give rise to differential diagnostic problems with $\mathrm{EH}$ or adenocarcinoma $[36,37]$. It seemed that the clear-cut definition of detailed nuclear findings was indispensable for an accurate LBC diagnosis in addition to the cytoarchitectural criteria in EGBD and G1.

The following discriminating nuclear features were further defined: (1) in CCSC of EGBD, the nuclei were characteristically small, of reniform or spindled shape, nuclear chromatin tended to be hyperchromatic, overlapping nuclei with nuclear crowding and the derangement of nuclear distribution were frequently found; (2) in MCIP of EGBD, larger, spindle-shaped nuclei are characteristic, with overlapping nuclei with nuclear crowding and the derangement of nuclear distribution; (3) concerning the clumps of cancer cells (CCC) in G1, roundoval nuclei appear to predominate, overlapping nuclei with nuclear crowding and the derangement of nuclear distribution are recognized $[56,57]$.

As for the degree of overlapping nuclei, CCSC showed a significantly higher value in comparison with CCC, and CCC did not show a significant difference in comparison with MCIP. Byren [34] reported that overlapping nuclei and nuclear crowding were 'useful' as diagnostic criteria for an endometrial malignant lesion, and $\mathrm{Ng}$ [58] described that nuclear overlapping and crowding may be evident in adenocarcinoma. The above-mentioned results emphasize the possibility of making a misdiagnosis among 
Fig. 5. Immunocytochemical staining. a PTEN in G1, the lack of staining was considered negative. $\mathbf{b} \beta$-Catenin in $\mathrm{G} 1$, the tumor cells show positivity in nuclei and cytoplasm. c $\beta$-Catenin in G3 adenocarcinoma, the loss of staining was considered a negative reaction. $\mathbf{d}$ p53 of papillary serous carcinoma, the tumor cells show strong p53 positivity in nuclei. SurePath LBP. Original magnification: $\times 40$ (a-d).

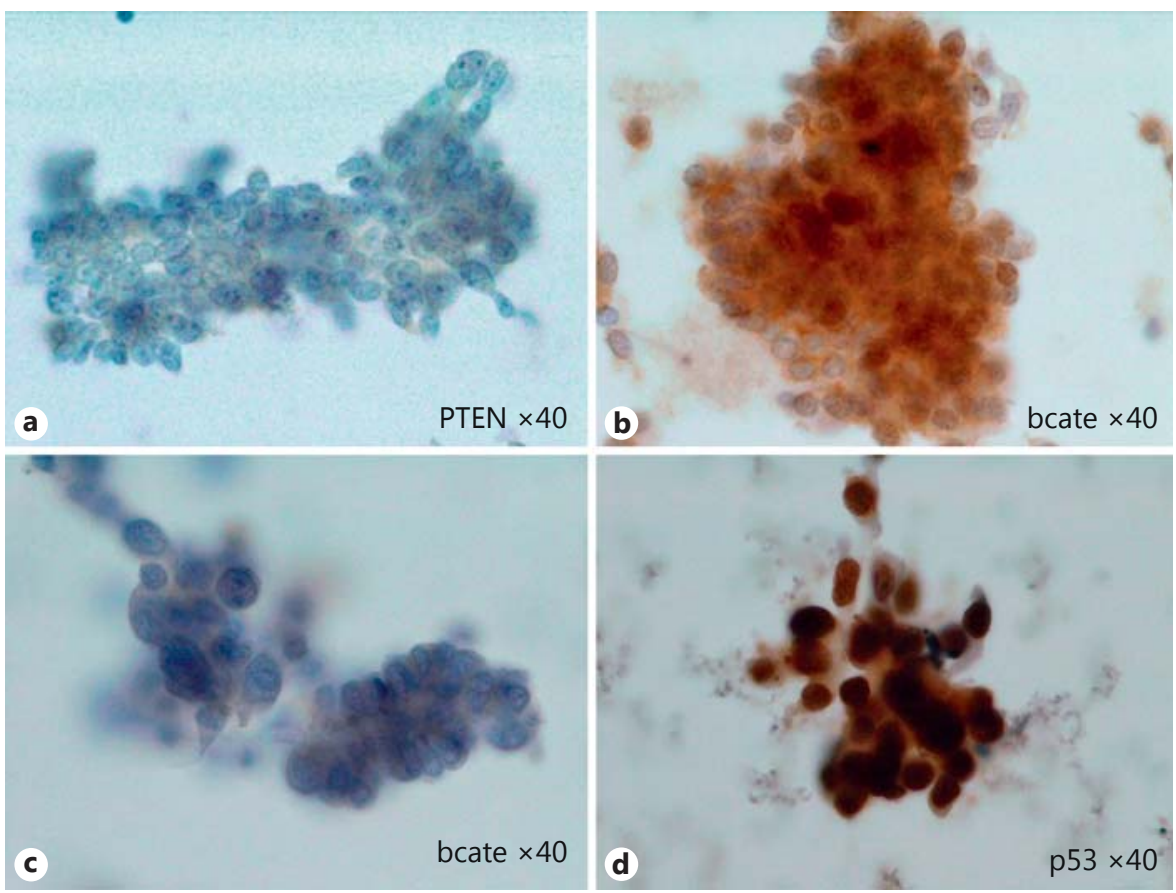

CCC, CCSC and MCIP. However, the nuclear shape features appear to be more useful in the discrimination between EGBD and G1 on LBPs. In the differential assessment of nuclear features in LBP versus conventional cytologic preparation (CCP) in EGBD cases, considering the spindle shape of the nucleus, only MCIP showed significantly higher values in LBP than in CCP, and as for the reniform shape of the nucleus, only CCSC showed significantly higher values in LBP compared with CCP [59].

With regard to the preservation of nuclear shape, it was considered that LBP was much better than CCP. In order to investigate the reason for these differences, for $\mathrm{CCP}$, an endometrial brush was rolled on a glass slide and the collected material was smeared. This operation carried with it several possible artifacts due to uneven smearing and or the fixation technique of the slide $[60,61]$. On the other hand, in LBP methods, the cells are evenly fixed in suspension with an alcoholic fixative while being mixed with it; in this way it is believed that the original size and shape of the nucleus is maintained [60].

\section{Immunocytochemistry Using Endometrial LBP}

Mutations of the PTEN, $\beta$-catenin and p53 genes are the most frequent molecular defects in type I and type II ECs [62-64]. Norimatsu et al. [65], in their study involv- ing evaluation of 38 cases of endometrial intraepithelial neoplasia, reported that immunohistochemical loss of PTEN and positive nuclear staining of $\beta$-catenin were frequently seen in endometrial intraepithelial neoplasia but not in normal PE cases. The combination of PTENnegative/ $\beta$-catenin-positive results may become a reliable marker for detecting endometrial intraepithelial neoplasia. Because the overexpression of gene products in types I and II carcinomas correlate with clinicopathological factors and prognosis, it is important to understand the expression of these gene products of normal endometrium, precancerous endometrium and carcinoma in immunocytochemistry by LBP.

\section{Diagnostic Utility of PTEN, $\beta$-Catenin and p53 for Endometrial Cancer}

In 2008, Norimatsu et al. [66, 67] attempted to examine the immunocytochemical expression of PTEN, $\beta$-catenin and p53 in benign endometrium and EC samples prepared by the LBP method. With regard to PTEN immunoreactivity, a cut-off value of 50\% of PTEN expression may be useful for an accurate diagnosis of EC in endometrial cytology (fig. 5a). For $\beta$-catenin immunoreactivity, the cytoplasmic and nuclear $\beta$-catenin expression (fig. 5b) and the loss of $\beta$-catenin expression (fig. 5c) may be useful for more accurate diagnosis of EC in endometrial cytology and may aid in the stratification of tu- 


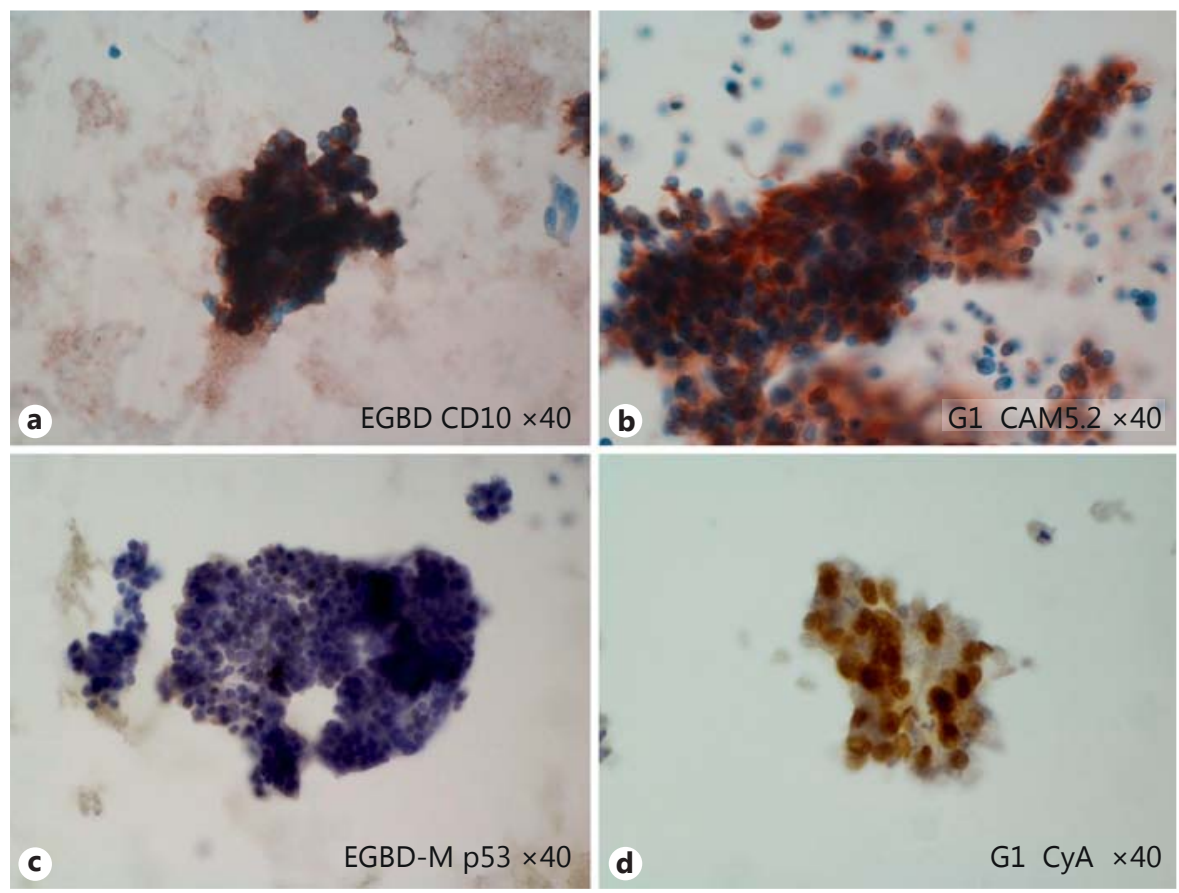

Fig. 6. Immunocytochemical staining. a CD10 and CCSC of EGBD shows brown staining of the cytoplasm. b Anticytokeratin (CAM 5.2) and CCC of G1 show brown cytoplasmic positivity. c p53 protein in MCIP of the EGBD case was comparatively weak. d Cyclin A and CCC of G1 show brown strong nuclear positivity. SurePath LBP. Original magnification: $\times 40(\mathbf{a}-\mathbf{d})$.

mor type. For p53 immunoreactivity, the application of a cut-off score of $>4$ for nuclear p53 expression may be useful for evaluating type II-EC in endometrial cytology (fig. 5d). It should be emphasized that the current immunocytochemical findings from the combination of PTEN, $\beta$-catenin and $\mathrm{p} 53$, along with cytomorphological features, appears to be a valuable tool for the identification of EC using LBP.

\section{Discrimination of EGBD and G1}

It is well known that CCSC and MCIP in EGBD cases may simulate CCC in G1, leading to difficulty in cytological interpretation $[40,49]$. Criteria based on characteristic findings of molecular biology as well as cytomorphological nuclear findings are hence necessary for a further improvement of the diagnostic accuracy. It was described that CD10 is a reliable and sensitive immunohistochemical marker of normal endometrial stroma and the CD10 and Wilms' tumor 1 protein (WT-1) positivity may be of value in diagnosis [68-70]. Of note, it was considered that cytokeratin (CAM 5.2) becomes a negative marker in this area (discrimination between endometrial stromal and smooth muscle tumors of the uterus) [71].

It was considered that the combination of the WT-1, CD10 and CAM5.2 may be a useful mix of markers to discriminate between CCSC and CCC. As a result of immunostaining, because CCSC was positive for CD10 (fig. 6a) and WT-1 and CCC was positive for CAM5.2 (fig. 6b), the discrimination was therefore possible [56]. Because p53 over-expression occurs more frequently in nonendometrioid type or poorly differentiated ECs with p53 mutation, p53 overexpression by immunostaining might be a useful screening method to diagnose ECs and to identify high-grade ECs [67, 72-74]. Cyclin A expression was involved in the progression to malignancy of the endometrium and was correlated with proliferative activity and prognostic features including histological grade, without coexisting $\mathrm{EH}$ and lymphovascular space involvement [75]. It was considered that the combination of p53 and cyclin A may be a useful marker to discriminate between MCIP and CCC. As for the immunoreactivity scores of $\mathrm{p} 53$ protein, CCC $(2.4 \pm 1.4)$ showed a significantly higher value compared with MCIP $(0.8 \pm 0.4$; fig. $6 \mathrm{c})$, and as for the immunoreactivity scores of cyclin A, CCC ( $2.8 \pm 1.1$; fig. $6 \mathrm{~d})$ showed a significantly high value compared with MCIP $(0.6 \pm 0.5)$ [76]. The obtained results speak in favor of a low precancerous risk of metaplastic changes.

CCSC and MCIP in EGBD are occasionally misinterpreted as cellular atypia and structural atypia $[40,49]$, but, based on the results of the immunoreactivity scores of p53 protein and cyclin A in our study, we reached the opinion that they have reparative or degenerative rather than preneoplastic potential. Therefore, the finding of low or 
Table 1. Descriptive reporting format for endometrial cytology for the Japanese Society of Clinical Cytology group study

\begin{tabular}{l} 
I $\begin{array}{c}\text { Specimen type } \\
\text { Conventional method, liquid-based method }\end{array}$ \\
\hline II $\quad \begin{array}{l}\text { Specimen adequacy } \\
\text { Satisfactory, unsatisfactory (rejected specimen, fully } \\
\text { evaluated, unsatisfactory specimen) }\end{array}$ \\
\\
\hline
\end{tabular}

III Result

Negative for malignancy

Endometrium in proliferative phase, in secretory phase, in menstrual phase, atrophic endometrium, benign reactive change (IUD, TAM, etc.), endometrial polyp, simple endometrial hyperplasia

ATEC: Atypical endometrial cells (ATEC-US or ATEC-A must be selected)

ATEC-US: Atypical endometrial cells, of undetermined significance

ATEC-A: Atypical endometrial cells, cannot exclude atypical endometrial hyperplasia, etc.

Endometrial hyperplasia Complex endometrial hyperplasia

Atypical endometrial hyperplasia

Atypical endometrial hyperplasia, endometrial

adenocarcinoma in situ, atypical polypoid adenomyoma

Malignant tumor

Endometrioid adenocarcinoma (G1, G2, G3, squamous

differentiation), serous adenocarcinoma, clear cell

adenocarcinoma, mucinous adenocarcinoma, squamous

cell carcinoma, mixed carcinoma, undifferentiated

carcinoma, mesenchymal tumors, endometrial stromal

sarcoma, leiomyosarcoma, carcinosarcoma, homologous

type, heterologous type, other malignant tumors,

extrauterine malignant tumors

IUD = Intrauterine device; TAM = tamoxifen.

Reproduced with permission [79].

weak p53 and cyclin A immunoreactivity in MCIP in EGBD is useful for discrimination between CCC and G1. It was considered that the addition of the above-described immunocytochemical panel to the cytomorphological features may be useful for a correct diagnosis of EGBD in endometrial cytology $[56,76]$.

\section{Reporting Format for Endometrial Cellular Diagnosis on Cytoarchitectural Criteria}

The most important role of any reporting system is to provide clarity for patient management. It is also important to be able to audit outcomes to refine and improve the reporting process, give a relative risk of endometrial can- cer for each cellular diagnosis, begin the process of a national standardization and compare with other systems used internationally. Any given diagnostic system must be easy to understand and to apply in clinical practice, and should show good intra- and interobserver reproducibility between the various categories. Recently, Yanoh et al. [77], and Kobayashi et al. [78] proposed that the new diagnostic reporting format for endometrial cytology based on cytoarchitectural criteria can be useful for the proper cellular assessment of endometrial lesions which is of great benefit to patients. Yanoh et al.'s subsequent report [79] showed that the new terminology used in the Japanese study group can be applied to the cytology practice with a satisfactory specificity for excluding cancer or precancerous lesions (table 1).

Once specimen adequacy has been assessed, the result can be categorized into five groups: (1) negative for malignancy; (2) atypical endometrial cells (ATEC); (3) EH; (4) atypical EH, and (5) malignant tumor. ATEC includes atypical cells of undetermined significance (ATEC-US) and ATEC, cannot exclude atypical EH or more (ATECA). ATEC-US is selected when ATEC are observed but their significance cannot be determined for some reason, possibly inflammatory, metaplastic, iatrogenic or any other changes causing cytomorphological alterations. In such cases, subsequent endometrial biopsy is usually not recommended unless the change persists on repeated cytology. ATEC-A is selected when the possibility of atypical $\mathrm{EH}$ or malignant tumor is not excluded mainly because of the limited number of atypical cells in the absence of inflammation, metaplastic changes or iatrogenic influences. In such cases, subsequent endometrial biopsy is recommended. All of these options should include additional information suggesting the histopathological diagnosis.

In a pilot study with diagnostic evaluation of the sensitivity and specificity of cytological examinations, we have recently shown how well the interpretations based on the morphologic findings in SurePath LBP using the criteria outlined agreed with the subsequent histologic diagnoses [80]. As a result, of the 122 cases, 4 specimens (3.3\%) were judged as unsatisfactory, all of which were due to scant cellularity. The sensitivity and specificity of SP-LBC endometrial cytology were 96.4 and 100\%, respectively, and its positive predictive value and negative predictive value were 100 and $98.9 \%$, respectively (table 2). A recent report demonstrated that preoperative dilatation and curettage remains the gold standard sample collection method (hysterectomy specimens) for diagnosing endometrial pathologies with sensitivity $(87.8 \%)$, specificity $(100 \%)$, positive $(100 \%)$ and negative 
Table 2. A pilot study of diagnostic evaluation $(\mathrm{n}=118)$

\begin{tabular}{cllll}
\hline & Sensitivity & Specificity & PPV & NPV \\
\hline SP-LBC & & & & \\
$\mathrm{n}$ & $27 / 28$ & $90 / 90$ & $27 / 27$ & $90 / 91$ \\
$\%$ & 96.4 & 100 & 100 & 98.9 \\
Conventional & & & \\
$\mathrm{n}$ & $328 / 415$ & $7,996 / 8,021$ & $328 / 353$ & $7,996 / 8,083$ \\
$\%$ & 79.0 & 99.7 & 92.9 & 98.9 \\
\hline
\end{tabular}

$\mathrm{PPV}=$ Positive predictive value; NPV = negative predictive value. Malignant tumor, atypical endometrial hyperplasia and ATECA interpretations were considered positive as evidence of malignancy.

(98.7\%) predictive values [81]. It is likely that SurePath LBP provides a good result compared with the conventional method [79] and biopsies [81]. The use of descriptive reporting format by LBP-endometrial cytology may be an acceptable and reliable diagnostic method not only for Japan, but also for the rest of the world, and may provide standardization. Therefore, we can expect more validation studies with the use of LBC method in endometrial cytology material in the near future.

\section{Conclusions}

In this report, we have shared the experience of the useful LBP method applied to the cellular diagnosis of endometrial lesions based on cytoarchitectural criteria. In the view of the complexity of the findings in normal endometrium and the range of pathological changes leading to endometrial cancer, the reporting of endometrial cytology, whether using conventional method or LBP, requires close contact between the reporting pathologist and the clinician responsible for the patient's care so as to ensure full understanding of the advantages and limitations of the cytological approaches $[82,83]$. This is best achieved by regular multidisciplinary meetings for discussing the patient's care in the light of the reports. Improved methods of obtaining adequate samples should make it possible for them to meet this challenge and establish a useful role for liquid-based endometrial cytology techniques in gynecological practice.

\section{Disclosures Statement}

The authors declare that they have no conflict of interest.

\section{References}

1 Jemal A, Siegel R, Ward E, Murray T, Xu J, Smigal C, Thun MJ: Cancer statistics, 2006. CA Cancer J Clin 2006;56:106-130.

2 Oncology Committee: Annual report on cervical, endometrial, and ovarian cancer. Acta Obst Gynaec Jpn 2007;61:913-995.

-3 Nakagawa-Okamura C, Sato S, Tsuji I, Kuramoto H, Tsubono Y, Aoki D, Jobo T, Oomura M, Hisamichi S, Yajima A: Effectiveness of mass screening for endometrial cancer. Acta Cytol 2002;46:277-283.

4 Geisinger KR, Stanley MW, Raab SS, Silverman JF, Abati A: Invasive glandular malignancies of the gynecologic tract; in Geisinger KR, Stanley MW, Raab SS, Silverman JF, Abati A (eds): Modern Cytopathology. Philadelphia, Churchill Livingstone, 2003, pp 147197.

5 Kobayashi H, Otsuki Y, Simizu S, Yamada M, Mukai R, Sawaki Y, Nakayama S, Torii Y: Cytological criteria of endometrial lesions with emphasis on stromal and epithelial cell clusters: result of 8 years of experience with intrauterine sampling. Cytopathology 2008; 19 : 19-27.

-6 Norimatsu Y, Shimizu K, Kobayashi TK, Moriya T, Tsukayama C, Miyake Y, Ohno E: Cellular features of endometrial hyperplasia and well-differentiated adenocarcinoma us- ing the Endocyte sampler: diagnositic criteria based on the cyto-architecture of tissue fragments. Cancer 2006;108:77-85.

7 Nambu M, Matsumoto S, Takeshita M, Nabeshima K, Iwashita A: A multivariate statistical study to obtain effective criteria to detect well-differentiated adenocarcinoma in endometrial cytology. Diagn Cytopathol 2012;40: 701-707.

8 Norimatsu Y, Kouda H, Kobayashi TK, Moriya $\mathrm{T}$, Yanoh $\mathrm{K}$, Tsukayama $\mathrm{C}$, Miyake $\mathrm{Y}$, Ohno E: Utility of thin-layer preparations in the endometrial cytology: evaluation of benign endometrial lesions. Ann Diagn Pathol 2008;12:103-111.

-9 Norimatsu Y, Kouda H, Kobayashi TK, Shimizu K, Yanoh K, Tsukayama C, Miyake Y, Ohno E: Utility of liquid-based cytology in endometrial pathology: diagnosis of endometrial carcinoma. Cytopathology 2009;20:395402.

10 Papaefthimiou M, Symiakaki H, Mentzelopoulou P, Giahnaki AE, Voulgaris Z, Diakomanolis E, Kyroudes A, Karakitsos P: The role of liquid-based cytology associated with curettage in the investigation of endometrial lesions from postmenopausal women. Cytopathology 2005;16:32-39.
1 Papaefthimiou M, Symiakaki H, Mentzelopoulou P, Tsiveleka A, Kyroudes A, Voulgaris Z, Tzonou A, Karakitsos P: Study on the morphology and reproducibility of the diagnosis of endometrial lesions utilizing liquidbased cytology. Cancer 2005;105:56-64.

-12 Nishimura Y, Watanabe J, Jobo T, Hattori M, Arai T, Kuramoto H: Cytologic scoring of endometrioid adenocarcinoma of the endometrium. Cancer 2005; 105:8-12.

13 Hattori M, Kobayashi TK, Nishimura Y, Machida D, Toyonaga M, Tsunoda S, Ohbu M: Comparative image analysis of conventional and thin-layer preparations in endometrial cytology. Diagn Cytopathol 2013;41:527532.

-14 Buccoliero AM, Gheri CF, Castiglione F, Garbini F, Barbetti A, Fambrini M, Bargelli G, Pappalardo S, Taddei A, Boddi V, Scarselli GF, Marchionni M, Taddei GL: Liquid-based endometrial cytology: cytohistological correlation in a population of 917 women. Cytopathology 2007;18:241-249.

15 Buccoliero AM, Castiglione F, Gheri CF, Garbini F, Fambrini M, Bargelli G, Pappalardo S, Scarselli G, Marchionni M, Taddei GL: Liquidbased endometrial cytology: its possible value in postmenopausal asymptomatic women. Int J Gynecol Cancer 2007;17:182-187. 
16 Weintraub J, Morabia A: Efficacy of a liquidbased thin layer method for cervical cancer screening in a population with a low incidence of cervical cancer. Diagn Cytopathol 2000;22:52-59.

17 Fremont-Smith M, Marino J, Griffin B, Spencer L, Bolick D: Comparison of the SurePath liquid-based Papanicolaou smear with the conventional Papanicolaou smear in a multisite direct-to-vial study. Cancer 2004 25;102: 269-279.

- 18 Bentz JS, Rowe LR, Gopez EV, Marshall CJ: The unsatisfactory ThinPrep Pap test: missed opportunity for disease detection? Am J Clin Pathol 2002;117:457-463.

$\checkmark 19$ Beerman H, van Dorst EB, Kuenen-Boumeester V, Hogendoorn PC: Superior performance of liquid-based versus conventional cytology in a population-based cervical cancer screening program. Gynecol Oncol 2009; 112:572-576.

20 Michael CW, McConnel J, Pecott J, Afify AM, Al-Khafaji B: Comparison of ThinPrep and TriPath PREP liquid-based preparations in nongynecologic specimens: a pilot study. Diagn Cytopathol 2001;25:177-184.

-21 Belsley NA, Tambouret RH, Misdraji J, Muzikansky A, Russell DK, Wilbur DC: Cytologic features of endocervical glandular lesions: comparison of SurePath, ThinPrep, and conventional smear specimen preparations. Diagn Cytopathol 2008;36:232-237.

-22 Norimatsu Y, Sakamoto S, Ohsaki H, Ozaki S, Yokoyama T, Shimizu K, Yanoh K, Akiyama M, Bamba M, Kobayashi TK: Cytologic features of the endometrial adenocarcinoma: comparison of ThinPrep and BD SurePath preparations. Diagn Cytopathol 2013;41: 673-681.

-23 Garcia F, Barker B, Davis J, Shelton T, Harrigill K, Schalk N, Meyer J, Hatch K: Thin-layer cytology and histopathology in the evaluation of abnormal uterine bleeding. J Reprod Med 2003;48:882-888.

24 Kurman RJ, Kaminski PF, Norris HJ: The behavior of endometrial hyperplasia: a longterm study of 'untreated' hyperplasia in 170 patients. Cancer 1985;56:403-412.

25 Meisels A, Jolicoeur C: Criteria for the cytologic assessment of hyperplasia in endometrial samples obtained by the Endopap endometrial sampler. Acta Cytol 1985;29:297-302.

26 Skaarland E: New concept in diagnostic endometrial cytology: diagnostic criteria based on composition and architecture of large tissue fragments in smears. J Clin Pathol 1986;39: $36-43$.

27 Coscia-Porrazzi LO: Cytologic criteria of hyperplastic lesions in endometrial samples obtained by the endocyte sampler. Diagn Cytopathol 1988;4:283-287.

28 Buckley CH, Fox H: Biopsy Pathology of the Endometrium, ed 2. New York, Arnold, 2002.
29 Scully RE, Bonfiglio TA, Kurman RJ, Silverber SG, Wilkinson EJ (eds): Histological Typing of Female Genital Tract Tumours: WHO International Histological Classification of Tumours, ed 2. New York, Springer, 1994, pp 1-189.

30 Ronnett BM, Kurman RJ: Precursor lesions of endometrial carcinoma; in Kurman RJ (ed): Blaustein's Pathology of the Female Genital Tract, ed 5. New York, Springer, 2001, pp 467-484.

31 Kurman RJ, Norris HJ: Evaluation of criteria for distinguishing atypical endometrial hyperplasia from well-differentiated carcinoma. Cancer 1982;49:2547-2559.

32 Silva M, Grinblat S, Sommers SC: 3-D reconstruction of endometrial carcinoma in situ. Am J Clin Pathol 1986;86:493-498.

33 Silverberg SG, Kurman RJ: Endometrial carcinoma, tumors of the uterine corpus and gestational trophoblastic disease; in Silverberg SG, Kurman RJ (eds): Atlas of Tumor Pathology, series 3. Washington, Armed Forces Institute of Pathology, 1992, pp 15-90.

34 Byren AJ: Endocyte endometrial smears in the cytodiagnosis of endometrial carcinoma. Acta Cytol 1990;34:373-381.

35 Morse AR: The value of endometrial aspiration in gynecological practice; in Koss LG, Coleman DV (eds): Advances in Clinical Cytology. London, Butterworth, 1981, pp 44-63.

36 Ehrmann RL: Atypical endometrial cells and stromal breakdown tow case reports. Acta Cytol 1975;19:465-469.

37 Sherman ME, Mazur MT, Kurman RJ: Benign disease of the endometrium; in Kurman RJ (ed): Blaustein's Pathology of the Female Genital Tract, ed 5. New York, Springer, 2001, pp 431-439.

- 38 Vakiani M, Vavilis D, Agorastos T, Stamatopoulos P, Assimaki A, Bontis J: Histopathological findings of the endometrium in patients with dysfunctional uterine bleeding. Clin Exp Obstet Gynecol 1996;23:236-239.

- 39 Livingstone M, Fraser IS: Mechanisms of abnormal uterine bleeding. Hum Reprod Update 2002;8:60-67.

-40 Shimizu K, Norimatsu Y, Kobayashi TK, Ogura S, Miyake Y, Ohno E, Sakurai T, Moriya T, Sakurai M: Endometrial glandular and stromal breakdown, part 1: cytomorphological appearance. Diagn Cytopathol 2006;34: 609-613.

41 Frenczy A: Pathophysiology of endometrial bleeding. Maturitas 2003;45:1-14.

42 Hendrickson MR, Kempson RL: Endometrial epithelial metaplasias: proliferations frequently misdiagnosed as adenocarcinoma: report of 89 cases and proposed classification. Am J Surg Pathol 1980;4:525-542.

43 Andersen WA, Taylor PT Jr, Fechner RE, Pinkerton JA: Endometrial metaplasia associated with endometrial adenocarcinoma. Am J Obstet Gynecol 1987;157:597-604.

-44 Kaku T, Tsukamoto N, Tsuruchi N, Sugihara K, Kamura T, Nakano H: Endometrial metaplasia associated with endometrial carcinoma. Obstet Gynecol 1992;80:812-816.
45 Jacques SM, Qureshi F, Lawrence WD: Surface epithelial changes in endometrial adenocarcinoma: diagnostic pitfalls in curettage specimens. Int J Gynecol Pathol 1995; 14:191197.

46 Ronnett BM, Kurman RJ: Precursor lesions of endometrial carcinoma; in Kurman RJ (ed): Blaustein's Pathology of the Female Genital Tract, ed 5. New York, Springer, 2001, pp 484-493.

47 Lehman MB, Hart WR: Simple and complex hyperplastic papillary proliferations of the endometrium: a clinicopathologic study of nine cases of apparently localized papillary lesions with fibrovascular stromal cores and epithelial metaplasia. Am J Surg Pathol 2001;25: 1347-1354.

48 Gribaudi G, Alasio L: Cytological changes caused by intrauterine devices. Pathologica 1981;73:207-216.

49 Norimatsu Y, Shimizu K, Kobayashi TK, Moriya T, Kaku T, Tsukayama C, Miyake Y, Ohno E: Endometrial glandular and stromal breakdown, part 2: cytomorphology of papillary metaplastic changes. Diagn Cytopathol 2006;34:665-669.

50 Zaman SS, Mazur MT: Endometrial papillary syncytial change: a nonspecific alteration associated with active breakdown. Am J Clin Pathol 1993;99:741-745.

-51 Norimatsu Y, Kawai M, Kamimori A, Yuminamochi T, Ohsaki H, Yanoh K, Kawanishi N, Kobayashi TK: Endometrial glandular and stromal breakdown, part 4: cytomorphology of 'condensed cluster of stromal cells including a light green body'. Diagn Cytopathol 2012;40:204-209.

52 Maksem JA, Robboy SJ, Bishop JW, Meiers I: Benign endometrial abnormalities; in Rosenthal DL (ed): Endometrial Cytology with Tissue Correlatioms, ed 1. New York, Springer Science and Business Media, 2009, pp 97-152.

53 Kuzu I, Bicknell R, Harris AL, Jones M, Gatter KC, Mason DY: Heterogeneity of vascular endothelial cells with relevance to diagnosis of vascular tumours. J Clin Pathol 1992;45:143148.

54 Sadler JE: A revised classification of von Willebrand disease. For the Subcommittee on von Willebrand Factor of the Scientific and Standardization Committee of the International Society on Thrombosis and Haemostasis. Thromb Haemost 1994;71:520-525.

55 Cranmer SL, Ulsemer P, Cooke BM, Salem $\mathrm{HH}$, de la Salle C, Lanza F, Jackson SP: Glycoprotein (GP) Ib-IX-transfected cells roll on a von Willebrand factor matrix under flow: importance of the GPIb /actin-binding protein (ABP-280) interaction in maintaining adhesion under high shear. J Biol Chem 1999 5; 274:6097-6106.

56 Norimatsu Y, Yuminamochi T, Shigematsu Y, Yanoh K, Ikemoto R, Masuno H, Murakami M, Kobayashi TK: Endometrial glandular and stromal breakdown, part 3: cytomorphology of 'condensed cluster of stromal cells'. Diagn Cytopathol 2009;37:891-896. 
57 Norimatsu Y, Shigematsu Y, Sakamoto S, Ohsaki H, Yanoh K, Kawanishi N, Kobayashi TK: Nuclear features in endometrial cytology: comparison of endometrial glandular and stromal breakdown and endometrioid adenocarcinoma grade 1. Diagn Cytopathol 2012; 40:1077-1082.

58 Ng ABP: Endpmetrial hyperplasia and carcinoma and extrauterine cancer; in Bibbo $\mathrm{M}$ (ed): Comprehensive Cytopathplogy, ed 2. Philadelphia: W.B. Saunders Company, 2001, pp 251-277.

-59 Norimatsu Y, Shigematsu Y, Sakamoto S, Ohsaki H, Yanoh K, Kawanishi N, Kobayashi TK: Nuclear characteristics of the endometrial cytology: liquid-based versus conventional preparation. Diagn Cytopathol 2013; 41:120-125.

60 Boon ME, Drijver JS: Comparing cells in histology and cytology; in Boon ME (ed): Routine Cytological Staining Techniques: Theoretical Background and Practice, ed 1. London, MaCmillian Education, 1986, pp 22-25.

61 Kaneko M: Fixation and the theory (in Japanese); in Tanaka N (ed): Textbook of Diagnostic Cytology: Its Fundamentals and Practice, ed 6. Tokyo, Uchudo Yagi-Shoten, 1979, pp 66-70.

-62 Wappenschmidt B, Wardelmann E, Gehrig A, Schöndorf T, Maass N, Bonatz G, Gassel AM, Pietsch T, Mallmann P, Weber BH, Schmutzler RK: PTEN mutations do not cause nuclear beta-catenin accumulation in endometrial carcinomas. Hum Pathol 2004; 35:1260-1265.

63 Lax SF: Molecular genetic pathways in various types of endometrial carcinoma: from a phenotypical to a molecular-based classification. Virchows Arch 2004;444:213-223.

64 Hech JL, Mutter GL: Molecular and pathologic aspects of endometrial carcinogenesis. J Clin Oncol 2006;24:4783-4791.

65 Norimatsu Y, Moriya T, Kobayashi TK, Sakurai T, Shimizu K, Tsukayama C, Ohno E: Immunohistochemical expression of PTEN and $\beta$-catenin for endometrial intraepithelial neoplasia in Japanese women. Ann Diagn Pathol 2007;11:103-108.

66 Norimatsu Y, Miyamoto T, Kobayashi TK, Oda T, Moriya T, Yanoh K, Miyake Y, Ohno E: Utility of thin-layer preparations in endometrial cytology: immunocytochemical expression of PTEN, $\beta$-catenin and p53 for benign endometrial lesions. Diagn Cytopathol 2008;36:216-223.
67 Norimatsu Y, Miyamoto M, Kobayashi TK, Moriya T, Shimizu K, Yanoh K, Tsukayama C, Miyake Y, Ohno E: Diagnostic utility of phosphatase and tensin homolog, $\beta$-catenin, and p53 for endometrial carcinoma by thin layer endometrial preparations. Cancer 2008; 114:155-164.

68 McCluggage WG, Sumathi VP, Maxwell P: $\mathrm{CD} 10$ is a sensitive and diagnostically useful immunohistochemical marker of normal endometrial stroma and of endometrial stromal neoplasms. Histopathology 2001;39:273-278.

69 Jung CK, Jung JH, Lee A, Lee YS, Choi YJ, Yoon SK, Lee KY: Diagnostic use of nuclear $\beta$-catenin expression for the assessment of endometrial stromal tumors. Mod Pathol 2008; 21:756-763.

70 Sumathi VP, Al-Hussaini M, Connolly LE, Fullerton L, McCluggage WG: Endometrial stromal neoplasms are immunoreactive with WT-1 antibody. Int J Gynecol Pathol 2004; 23:241-224

-71 Oliva E, Young RH, Amin MB, Clement PB: An immunohistochemical analysis of endometrial stromal and smooth muscle tumors of the uterus: a study of 54 cases emphasizing the importance of using a panel because of overlap in immunoreactivity for individual antibodies. Am J Surg Pathol 2002;26:403-412.

72 Shiozawa T, Xin L, Nikaido T, Fujii S: Immunohistochemical detection of cyclin A with reference to p53 expression in endometrial endometrioid carcinomas. Int J Gynecol Pathol 1997;16:348-353.

73 Shih HC, Shiozawa T, Kato K, Imai T, Miyamoto T, Uchikawa J, Nikaido T, Konishi I: Immunohistochemical expression of cyclins, cyclin-dependent kinases, tumor-suppressor gene products, Ki-67, and sex steroid receptors in endometrial carcinoma: positive staining for cyclin $\mathrm{A}$ as a poor prognostic indicator. Hum Pathol 2003;34:471-478.

74 Kounelis S, Kapranos N, Kouri E, Coppola D, Papadaki H, Jones MW: Immunohistochemical profile of endometrial adenocarcinoma: a study of 61 cases and review of the literature. Mod Pathol 2000;13:379-388.
5 Kyushima N, Watanabe J, Hata H, Jobo T, Kameya T, Kuramoto $\mathrm{H}$ : Expression of cyclin A in endometrial adenocarcinoma and its correlation with proliferative activity and clinicopathological variables. J Cancer Res Clin Oncol 2002;128:307-312.

76 Norimatsu Y, Ohsaki H, Yanoh K, Kawanishi N, Kobayashi TK: Expression of immunoreactivity of nuclear findings by $\mathrm{p} 53$ and cyclin a in endometrial cytology: comparison with endometrial glandular and stromal breakdown and endometrioid adenocarcinoma grade 1. Diagn Cytopathol 2013;41:303-307.

77 Yanoh K, Norimatsu Y, Hirai Y, Takeshima N, Kamimori A, Nakamura Y, Shimizu K, Kobayashi TK, Murata T, Shiraishi T: New diagnostic reporting format for endometrial cytology based on cytoarchitectural criteria. $\mathrm{Cy}$ topathology 2009;20:388-394.

78 Kobayashi TK, Norimatsu Y, Buccoliero AM: Cytology of the body of the uterus; in Gray W, Kocjan G (eds): Diagnostic Cytopathology, ed 3. London, Churchill Livingstone, 2010, pp 689-719.

79 Yanoh K, Hirai Y, Sakamoto A, Aoki D, Moriya $T$, Hiura $M$, Yamawaki $T$, Shimizu $K$, Nakayama H, Sasaki H, Tabata T, Ueda M, Udagawa Y, Norimatsu Y: New terminology for intrauterine endometrial samples: a group study by the Japanese Society of Clinical Cytology. Acta Cytol 2012;56:233-241.

80 Yanoh K, Norimatsu Y, Munakata S, Yamamoto T, Nakamura Y, Murata T, Hirai Y, for the Osaki Study Group (OSG): A pilot study examining the sensitivity and specificity of cytological examinations of uterine endometrium samples prepared with the SurePath method. Acta Cytol 2013, submitted.

-81 Barut A, Barut F, Arikan I, Harma M, Harma MI, Ozmen Bayar U: Comparison of the histopathological diagnoses of preoperative dilatation and curettage and hysterectomy specimens. J Obstet Gynaecol Res 2012;38:16-22.

82 Jimenez-Ayala M: New terminology for intrauterine endometrial samples: a group study by the Japanese society of cytology. Acta Cytol 2013;57:113-114.

83 Yanoh K, Hirai Y, Sakamoto A, Aoki D, Moriya $T$, Hiura $M$, Yamawaki $T$, Shimizu $K$, Nakayama H, Sasaki H, Tabata T, Ueda M, Udagawa Y, Norimatsu Y: Authors' reply. Acta Cytol 2013;57:114. 